\title{
Cognitive Effects of Physical Support Systems: A Study of Resulting Effects for Tasks at and above Head Level Us- ing Exoskeletons
}

\author{
Felix Schroeter ${ }^{1}$, Svantje T. Kähler ${ }^{1}$, Zhejun $\mathrm{Yao}^{2}$, Thomas Jacobsen ${ }^{1}$ and Robert \\ Weidner ${ }^{2,3}$ \\ ${ }^{1}$ Helmut-Schmidt University Hamburg, Experimental Psychology Unit, Holstenhofweg 85, \\ 22043 Hamburg, Germany \\ ${ }^{2}$ Helmut-Schmidt University Hamburg, Laboratory of Manufacturing Technology, Holstenhof- \\ weg 85, 22043 Hamburg, Germany \\ ${ }^{3}$ University Innsbruck, Technikerstr. 13, 6020 Innsbruck, Austria
}

\begin{abstract}
In the wake of demographic change and increasing knowledge of potentially harmful activities and work areas, technical support systems like exoskeletons are used to minimize the risk of musculoskeletal disorders (MSDs) by supporting employees during tasks with high biomechanical load. In addition, the increasing quality requirement and individualized demand make production activities more complex and changeable. Not least because of the well-trained abilities and skills of humans, employees have a central role in current and future value chains. One possibility for physically supporting manual tasks is the exoskeleton. During the development and implementation of the exoskeletons, many of their effects and performances have been evaluated. Mostly, developers or end-users focus on selected biomechanical effects like reduction of musculoskeletal stress. The effects on cognitive structures as well as the impact on work quality are less known. The current study analyzed the cognitive effects during the use of the active exoskeleton Lucy for tasks performed at or above head level in a real environment (training center for scaffolders). The study was conducted with 18 participants. Our experiment was able to show that participants who were supported by the exoskeleton Lucy made significantly fewer mistakes in a work task $(53,8 \%)$. In addition, a significantly higher cognitive performance (concentration achievement, processing of target objects and error frequencies) was found in supported participants, compared to the unsupported condition, in a psychometric test after each work task.
\end{abstract}

Keywords: exoskeleton, support system, concentration performance, resulting effects, industrial application 


\section{$1 \quad$ Introduction}

Despite the increasing demand in automation production tasks, humans have a central role in common, future value chains, and organizational structure [1]. The reason can be seen in the unique skills and abilities of the human perception, cognition and motor skills which are still superior to automated solutions in many areas, such as flexibility, sensorimotor skills, cognition and learning abilities, and attentive perception. On the other hand, we still have other areas, where automated solutions are advantageous, e.g. high endurance and accuracy, arithmetic operations or memory capacity.

To support human beings during manual tasks, different approaches are possible, to offer different types of support. They can strengthen the position or substitute the employee [2]. In general, such support technologies can be arranged parallel or serial to the user and support the user in physical and cognitive aspects, e.g., [3-5]. In this paper, we address an exoskeleton, which can be classified as a parallel system. Such systems are characterized by a force path parallel to the human musculoskeletal system. The use of technical support systems in the field of, e.g., production, logistics, and the handcraft may be motivated in different ways. Central drivers are the organizations or the employee. Support systems can be used to increase quality and productivity or decrease musculoskeletal stress and thus the potential for musculoskeletal disorders.

In general, exoskeletons are designed to achieve task-individual properties. In respect to the desired properties, such systems are different in kinematic structure, human-machine-interfaces and actuation, as well as (in the case of active systems) sensors and control units [5]. Depending on the basic concept of each exoskeleton, such systems can support different kinds of tasks. Typical applications of exoskeletons in industrial areas are supporting tasks at head level or above, handling loads, gripping activities or handling tools and components [6-12].

The benefit of a mechanical relief for the workforce seems most obvious. Not least because the mechanical strain caused by the nature of the work task, such as working at head level or above, or handling heavy loads, could lead to fatigue and chronic complaints in the workforce (musculoskeletal diseases) [13]. These negative consequences must be avoided at all costs in order to be able to fulfill the central requirement of the work task: to be able to work without any impairment or damage $[13,14]$.

At this point, it should be emphasized that working at or above head level is an unfavorable working position for people, but is justified due to the requirements of production and cannot be changed in its actual execution. This may lead to the development of pain, which can also become chronic in the future [15]. A reduction in cognitive performance, which may be reflected, for example, in impaired memory function is directly related to chronic overload as the result of permanent physical strain. In particular, these consequences are the reason for the development of technical support systems for industrial production [16].

The performance of exoskeletons and their ability to reduce physical stress during manual activities has been shown in previous research [7, 9-12]. However, their influence on worker's cognitive performance and working quality are less known. The relationship between the levels of perceived pain and reduced cognitive and physical per- 
formance have been discussed extensively in psychological literature [17]. The investigation of the impact of physical support of an exoskeleton on specifically cognitive performance a rather new field in both psychology and production engineering. Psychometric testing is necessary for the collection of objective data measuring cognitive performance. Here, the relationship between the test and the experimental objective was considered to allow a valid quantitative evaluation. Thus, in addition to measuring work task duration and therein occurring errors, the latest version of the $\mathrm{d} 2-\mathrm{R}$ Attention and Concentration Test was chosen as the central psychometric measuring device for data collection, which meets the above requirements. The abbreviation $\mathrm{d} 2-\mathrm{R}$ refers to the target item " $d$ " with two bars that is intermixed with $d, p$ and b with different amount of bars above and/or under the letters ("R" stands for revised). According to the manual of the d2-R Attention and Concentration Test, this psychometric test presents as valid and reliable. According to the TBS TK review (Testbeurteilungssystem des Testkuratoriums der Föderation Deutscher Psychologenvereinigungen), the d2-R Attention and Concentration is suitable for the evaluation of levels of concentration. Thus, all central criteria regarding concentration level following the work task could be recorded [18].

This paper reports a further study, focusing on the investigation of the influence of support systems on human cognitive function in a work place setting. For this purpose, participants performed a task with and without the support system. Afterwards a psychometric test procedure was carried out. A detailed description of the study design, including task setups, observed variables, statistical analysis and results can be found below.

\section{Study design}

The aim of this study was to analyze the effects of a physical support system on human cognitive function, especially the concentration levels, the treatment of target objects and corresponding error frequency in a psychometric test, and performance during a working task. In a previous publication it has been shown, that the exoskeleton Lucy successfully reduced physical stress [8] and improved the participants' levels of concentration [19]. To investigate whether the physical relief effect of Lucy may lead to improvements in participants' cognitive abilities within a workplace setting, testing was performed under realistic conditions in a training center for scaffolders.

Key hypotheses were:

- The physical support of an exoskeleton decreases the performance errors in the $\mathrm{d} 2-\mathrm{R}$ test, and in turn increases concentration levels and the number of processed target objects within a considered time unit of the $\mathrm{d} 2-\mathrm{R}$ test.

- The physical support from exoskeletons decreases the occurrence of errors in the work task performed.

\subsection{Exoskeleton Lucy}

The exoskeleton Lucy [7] was used, which is illustrated in Figure 2. It is worn like a backpack and supports the user during movements at head level and above. It uses 
pneumatic actuators to partially absorb and dissipate the additional workload, caused by and dependent on the tasks performed. In order to realize a natural level of support, predefined force curves are implemented in the control system. A detailed technical description can be found in previous work [7]. The user is able to change the level of support manually and individually applicable to each task. For standardization of the tests, all participants used the same level of support parameters. Hereby the level of support was set to approximately $4 \mathrm{~kg}$ with a shoulder angle of $90^{\circ}$.

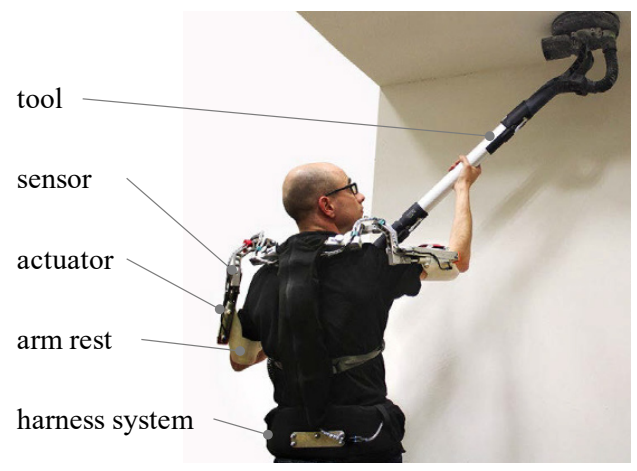

Figure 2. Exoskeleton Lucy for support tasks at head level and/or above.

\subsection{Experimental setup}

To investigate the hypotheses, 18 male participants performed a given task in a standardized manner. Participants were all second-year trainees within the scaffolding construction industry. Due to the absence of female trainees, it was not possible to acquire a gender-balanced sample for the survey-period. Mean age was 22.55 years ( $S D$ = 5.79; range: 17-39 years). Participants' height ranged from 170 to $190 \mathrm{~cm}$.

In order to determine the interventional effects of the exoskeleton, participants were randomly allocated to one of two interventional groups. Participants with odd participant number were assigned in Group 1 and with even participant number in Group 2. Group 1 began the work task with the Lucy system and then performed the same task in an unsupported condition. Participants of Group 2, began in the unsupported and then ended in the supported condition. Participants were instructed to take a break of 10 minutes between the two conditions, respectively. During this time, participants were able to recover from the previous work task as well as from the concentration test. Thereby equal starting points were created for each experimental condition. For the d2$R$ concentration test a total of 14 consecutive letter rows consisting of " $d$ " and "p" were shown to the participants in a pen and paper test. The task was to find and cross out the letters "d", which were marked with two dashes in the standardized interval of $20 \mathrm{sec}$ onds for each line. After the acoustic signal "Stop! Next line!" was given, participants had to move on to the next line following the same procedure as previously. This procedure is in accordance with the manual of $\mathrm{d} 2-\mathrm{R}$ and took overall 280 seconds. To assess the effects of the intervention on concentration, participants performed another 
$\mathrm{d} 2-\mathrm{R}$ concentration test in both conditions immediately after completing the work task (see Table 1.).

Table 1. Experimental setup.

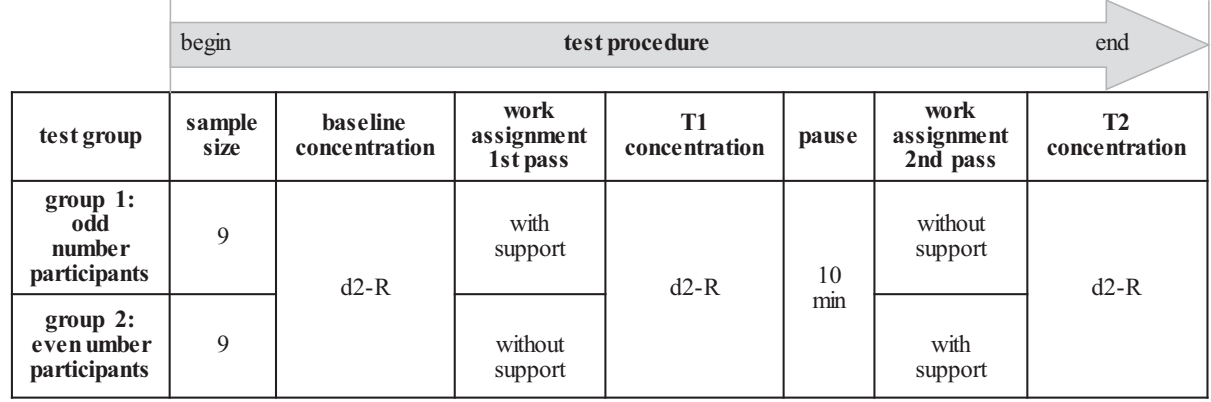

A standard scaffold was erected, as it is in real life settings (i.e. facades). For the experiment, eight crossbars including type-related fuses and a standard carpenter's hammer, for hammering in the fuses, were used. A complete crossbar weighed 3.5 kilograms and was 1 meter long. All participants were familiar with the materials and methods used in the work task. The work task was designed after an everyday occurrence within the scaffolding industry, consisting of inserting eight crossbars onto the highest level of the scaffold, hammering two fuses into each crossbar. The installation of one crossbar contained three steps (see Figure 1):

1. receiving the crossbar from a colleague on the floor below

2. positioning the crossbar on the highest installation level ( 2 meters from the running board)

3. fixing the crossbar by hammering in two fuses at either end of the board

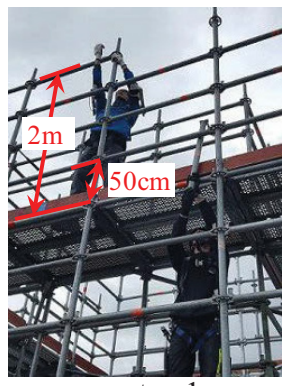

step 1

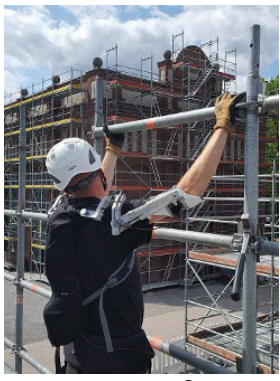

step 2

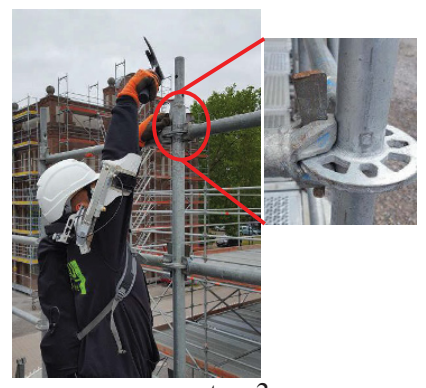

step 3

Figure 1. Installation steps of a crossbar at the highest installation level which is 2 meters high from the running board. 
During each installation, the crossbar was held at knee, hip, chest, and overhead level. The highest installation level was 2 meters from the running board (see Figure 1). This was considered overhead level for all participants. The final installation step was perceived as the most physically demanding step by all participants, since both the crossbar and the hammer required excessive forces above head level. It was therefore chosen as the condition in which the errors during the working task (ErrorWT) were counted. Additionally, and more importantly for this study, Lucy showed to deliver the greatest level of support at overhead level.

\subsection{Observed variables}

To assess the impact on cognitive function after each run of the experimental conditions (supported/unsupported), measurements of concentration performance, accuracy in $\mathrm{d} 2-\mathrm{R}$ test processing (error frequency) and speed in test processing (detected targets) were obtained using the $\mathrm{d} 2-\mathrm{R}$ Attention and Concentration Test [20] as quantitative parameter. Additionally, the errors during the working task (ErrorWT) were defined as hits missing the fuse.

Concentration performance (KL) was used as measure of concentration capability. In the test this described the number of crossed-out target objects, minus the number of wrongly marked objects. The processed target objects (BZO) were determined by the working speed. It was measured by the number of processed target objects of the $\mathrm{d} 2 \mathrm{R}$ in a given test period. Error frequency (F) was defined as the accuracy during test processing and was indicated by correctly processed items. Therefore, high values in the error frequency meant better results than smaller ones.

\subsection{Statistical Analysis}

Four t-tests were conducted for this study. Three were used to analyze baseline data, determining whether there were significant differences between the two groups (separated for Working Order) prior to our experiment in the three variables of the d2-R. Another was used to see if the required working time for the same task under two conditions (supported, unsupported) differed from each other. To assess the effects of the Lucy for the two factors, the method Analysis of Variance (ANOVA) was used. An ANOVA was calculated for the three dependent variables of the d2-R (KL, BZO, F) each, and one for the errors occurring during the work task (ErrorWT). Each ANOVA had the same mixed within-between design with repeated measurement on the withinsubjects factor Support (supported, unsupported) and the between-subjects factor Working Order (Group 1, Group 2). With the within-subjects factor the difference between the two conditions with and without the support of the exoskeleton was estimated. The between-subjects factor indicated whether Working Order of supported and unsupported condition (Group 1, Group 2) had a significant effect. The interaction effect of the two main factors could assess, if the effect of support was modulated by the Working Order.

The experimental data were analyzed and evaluated using the software RStudio (R3.6.1) (RStudio, 2012). For standardization of the d2-R values, norm tables printed in 
the manual were used, considering the different age groups. The $\mathrm{d} 2-\mathrm{R}$ Attention and Concentration Test was standardized from the end of 2007 to mid-2008. The manual for the $\mathrm{d} 2-\mathrm{R}$ test did not provide more detailed information on the standardized period. Altogether 4024 persons with an almost balanced gender ratio (50.7\% male, 49.4 female) formed the basis for the standardization [20].

\section{$3 \quad$ Results}

The analysis of the t-test regarding the $\mathrm{d} 2-\mathrm{R}$ baseline showed that there were no significant group differences as a function of Working Order for the concentration performance $(\mathrm{KL}) t(16)=1.81, p=.09$, the processed target objects $(\mathrm{BZO}) t(16)=1.88, p$ $=.084$, as well as for the error frequency $(\mathrm{F} \%) t(16)=1.41, p=.18$. The degrees of freedom (in brackets) of the t-test and ANOVA are an estimate of the number of independent information that went into calculating the estimated t-value. For the calculation of a between-group design the amount of groups (here 2) are subtracted from the sample size (18). The non-significant results of our analyses $(p>.05)$ indicated that the null hypothesis could not be rejected and we could assume our groups had the same level of concentration prior to the experiment. The t-test of the time on task for conditions supported $($ mean $=150.61 \mathrm{~s})$ and unsupported $($ mean $=132.17 \mathrm{~s})$ differed significantly $(t(16)=2.13, p=.04)$.

The results of the four within-subjects ANOVA's for the variable Support (supported, unsupported) are summarized in Table 2. An effect size ( $\eta$ p2) of .01 is considered as small, .06 as medium and .14 large [21]. All four dependent variables (KL, BZO, F and ErrorWT) showed significant main effects for the factor Support. Participants in the supported condition achieved better values in the dependent variables of the $\mathrm{d} 2-\mathrm{R}$ and lower error counts in the work task, than participants in the unsupported condition. This suggests a positive influence of Lucy on the wearers. The main effect for Working Order did not reach statistical significance in any of the ANOVAs.

Table 2. Summary of the main effects Support (supported, unsupported) of the Analysis of Variances (Support x Working Order).

\begin{tabular}{|l|l|l|l|l|l|l|}
\hline $\begin{array}{l}\text { observed } \\
\text { variables }\end{array}$ & $\begin{array}{l}\text { supported } \\
\text { (mean) }\end{array}$ & $\begin{array}{l}\text { unsup- } \\
\text { ported } \\
\text { (mean) }\end{array}$ & $\begin{array}{l}\text { F-value } \\
\boldsymbol{F}(\mathbf{1 , 1 6})\end{array}$ & $\begin{array}{l}\text { signifi- } \\
\text { cance } \\
\text { value } \boldsymbol{p}\end{array}$ & $\begin{array}{l}\text { mean } \\
\text { squared } \\
\text { error } \\
\boldsymbol{M S E}\end{array}$ & $\begin{array}{l}\text { effect } \\
\text { size } \\
\boldsymbol{\eta} \boldsymbol{p}^{\mathbf{2}}\end{array}$ \\
\hline $\begin{array}{l}\text { concentration per- } \\
\text { formance (KL, d2-R) }\end{array}$ & 103.28 & 98.28 & 65.45 & $<.0001$ & 3.44 & .80 \\
\hline $\begin{array}{l}\text { processed target ob- } \\
\text { jects (BZO, d2-R) }\end{array}$ & 102.22 & 97.83 & 56.87 & $<.0001$ & 3.05 & .78 \\
\hline $\begin{array}{l}\text { error frequency } \\
\text { (F, d2-R) }\end{array}$ & 104.56 & 100.33 & 12.25 & .003 & 13.1 & .43 \\
\hline $\begin{array}{l}\text { errors in the work } \\
\text { task (ErrorWT) }\end{array}$ & 6.5 & 3.5 & 24.92 & $<.001$ & 3.25 & .61 \\
\hline
\end{tabular}


The results of the interaction term of the four ANOVA's between-subject factor Working Order (Group 1, Group 2) as a function of Support (supported, unsupported) are displayed in Table 3. The results show that Working Order had a significant interaction effect on Support for the variables concentration performance and the processed target objects, but neither on the effect of support on the error frequency of the $\mathrm{d} 2-\mathrm{R}$, nor on the errors in the work task. The significant interaction between Working Order and Support for the variables KL and BZO were due to the better values in the supported condition, when the participants had already executed the task in the unsupported condition (Group 2), compared to when participants started in the supported condition (Group 1, see Figure 3).

Table 3. Summary of the interaction effects (supported, unsupported x Group 1, Group 2) of the Analysis of Variances (Support x Working Order)

\begin{tabular}{|l|l|l|l|l|}
\hline observed variables & $\begin{array}{l}\text { F-value } \\
\boldsymbol{F}(\mathbf{1 , 1 6})\end{array}$ & $\begin{array}{l}\text { significance } \\
\text { value } \boldsymbol{p}\end{array}$ & $\begin{array}{l}\text { mean squared } \\
\text { error } \boldsymbol{M S E}\end{array}$ & $\begin{array}{l}\text { effect size } \\
\boldsymbol{\eta} \boldsymbol{p}^{2}\end{array}$ \\
\hline $\begin{array}{l}\text { concentration } \\
\text { performance (KL, d2-R) }\end{array}$ & 23.56 & .0002 & 3.44 & .6 \\
\hline $\begin{array}{l}\text { processed target objects } \\
\text { (BZO, d2-R) }\end{array}$ & 20.13 & .0004 & 3.05 & .56 \\
\hline $\begin{array}{l}\text { error frequency } \\
\text { (F, d2-R) }\end{array}$ & 1.22 & .29 & 13.1 & .07 \\
\hline $\begin{array}{l}\text { errors in the work task (Er- } \\
\text { rorWT) }\end{array}$ & .31 & .59 & 3.25 & .02 \\
\hline
\end{tabular}

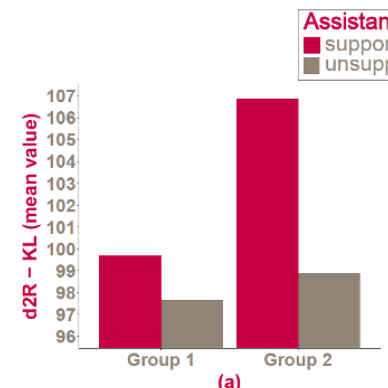

(a)

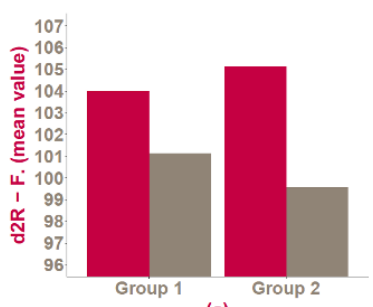

(c)

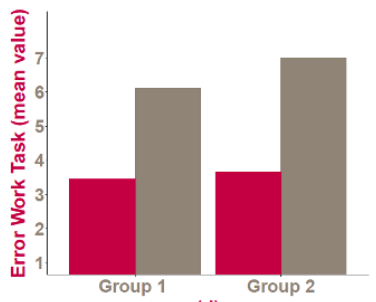

(d)

Figure 3. Interaction plots of (a) concentration performance (KL), (b) processed target objects (BZO) and (c) error frequency (F) of the d2-R test, as well as (d) errors during work task (ErrorWT). Group 1 had a working order of changing from supported to unsupported, while the Group 2 worked in a reversed order. 


\section{Discussion}

To evaluate the effects of a physical support system on cognitive function in a field setting (work place of scaffold trainees), the above study assessed participants' performance in a psychometric concentration test (d2-R) and the errors made in the work task. The results of the study showed significantly better concentration performance, processed target objects, and the error frequency in the $\mathrm{d} 2-\mathrm{R}$ test as well as the errors in the work task, when participants were supported by the exoskeleton Lucy, compared to the unsupported condition. This may be an indication, that the decrease in physical strain through Lucy could improve cognitive performance of the user, compared to an unsupported condition. To rule out order-effects, the experiment was run in two methodological conditions (supported first, unsupported first) each with a subset of the sample. The comparison of the standard values in the $\mathrm{d} 2-\mathrm{R}$ baseline measurement between the two groups did not reach statistical significance for each variable of the $\mathrm{d} 2-\mathrm{R}$. Thus, the effects of the support system on the dependent variables for concentration and order-effects could not be attributed to pre-experimental group differences. For the variable concentration performance and processed target objects, the interaction effect of Support and Working Order reached statistical significance. The group, which first performed the work task without support, followed by the supported condition performed better, compared to the group starting in the supported condition. Based on two of the three dependent measures derived from the $\mathrm{d} 2-\mathrm{R}$, this may indicate that the beneficial effect of support on concentration was strongest, when participants had already performed the work task once before. This could be due to practice-effects regarding the experimental setting, or differences between the groups, that could not be ruled out with the baseline measurement. As displayed in Figure 3 none of the values of the supported conditions were significantly lower than in the unsupported condition of each group (it must be noted that the interaction effect of error frequency in the $\mathrm{d} 2 \mathrm{R}$ did not reach statistical significance). Therefore, comparing the two conditions (supported, unsupported) within each group, the performance was enhanced for every variable in the supported condition. In this context, it must also be discussed whether the above-mentioned results of the experiment can be attributed to the fact that participants took significantly more time to perform the work task in the supported condition than in the unsupported condition. Similar response patterns were commonly found in a variety of tasks, allowing the person to set a criterion for speed at the expanse of accuracy, termed speedaccuracy trade off (for an overview see [22]). To eliminate this possible covariate, the differing time spent on tasks with and without the exoskeleton should be aligned in subsequent studies, for example with a familiarization phase, as the blocks might have been too short to adapt to the unfamiliar exoskeleton. Nevertheless, as the effect sizes for the benefit of support were large and the prior study [19] found the beneficial effect of support on concentration and errors without speed differences between the conditions (supported, unsupported), the speed-accuracy trade-off should not account exclusively for supporting effect of the exoskeleton on concentration enhancement and error decrement. 


\section{Conclusion}

The exoskeleton Lucy improved the working results of the participants in the above study. A large number of further studies on this topic is necessary to achieve an optimized fit between user and technical support systems in the future.

The present study showed that a technical support system in this particular setting presents a meaningful addition to the workforce, with regards to a higher concentration capacity and error avoidance in comparison to working without such a system. In addition, mechanical relief may contribute to health-promoting work. The urgency to investigate this topic area further with relevance to social and economic contexts. Psychological research may also play a greater role in the development and evaluation of exoskeletons, emphasizing the importance of interdisciplinary approaches.

However, errors in the work process can never be completely avoided in practice and physically demanding tasks and occupations, such as those in the scaffolding industry, will likely remain unchanged in the future. Nevertheless, the results show that the use of technical support systems may be considered in the industrial sector as a whole, under aspects of concentration levels and error avoidance.

\section{Acknowledgements}

This research was partially conducted in the project "Smart ASSIST Smart, Adjustable, Soft and Intelligent Support Technologie" (16SV7114) and funded by the Federal Ministry of Education and Research (BMBF) program for an interdisciplinary build-up of competence in human machine interaction for demographic changes. Supervision is provided by VDI/VDE INNOVATION GmbH. The sole responsibility for the manuscript contents lies with the authors.

The authors would like to thank Victoria Edwards for proofreading the manuscript.

\section{References}

1. W. MacDougall: Industrie 4.0: Smart manufacturing for the future. Germany Trade \& Invest, 2014.

2. R. Weidner, A. Karafillidis: Three General Determinants of Support-Systems. In: Applied Mechanics and Materials Vol. 794 (2015), S. 555 - 562, Trans Tech Publications, Schweiz, doi:10.4028/www.scientific.net/AMM.794.555, 2015.

3. R. Weidner, N. Kong, J. P. Wulfsberg: Human Hybrid Robot: a new concept for sup-porting manual assembly tasks. In: Production Engineering, 7(6), S. 675-684, DOI: 10.1007/s11740-013-0487-x, 2013.

4. R. Weidner, T. Redlich, J. P. Wulfsberg: Technische Unterstützungssysteme. Springer-Verlag, Berlin, ISBN: 978-3-662-48382-4, 2015.

5. R. Weidner: Technische Unterstützungssysteme, die die Menschen wirklich wollen. Band zur zweiten Transdisziplinären Konferenz, ISBN: 978-3-86818-089-3, 2016.

6. K. Stadler: Exoskeletons: von der akademischen Vision zur industriellen Anwendung. In Internationales Forum Mechatronik, Winterthur, 2013. 
7. B. M. Otten, R. Weidner, A. Argubi-Wollesen: Evaluation of a novel active exoskeleton for tasks at or above head level," IEEE Robotics and Automation Letters, vol. 3(3), pp.24082415, Jul. 2018.

8. C. Berger, A. Argubi-Wollesen, R. Weidner: Biomechanical Analysis of a Wearable Support Device for Overhead Work. European College of Sports Science Congress. Wien, 6.-9. Juli 2016.

9. Z. Yao, C. Linnenberg, A. Argubi-Wollesen, R. Weidner, J.P., Wulfsberg: Biomimetic design of an ultra-compact and light-weight soft muscle glove. In: Production Engineering, vol. 11(6), pp.731-743, Dec. 2017.

10. M. Wehner, D. Rempel, H. Kazerooni: Lower extremity exoskeleton reduces Back forces in lifting, in: ASME 2009 Dynamic Systems and Control Conf., vol. 2, pp. 49-56, 2009.

11. S. Toxiri, J. Ortiz, J. Masood, J. Fernandez, L. A. Mateos, D. G. Caldwell: A wearable device for reducing spinal loads during lifting tasks: biomechanics and design concepts. In: 2015 IEEE Int. Conf. on Robotics and Biomimetics (ROBIO), pp. 2295-2300, 2016.

12. Z. Yao, C. Linnenberg, R. Weidner, J. Wulfsberg: Development of A Soft Power Suit for Lower Back Assistance. In: 2019 IEEE International Conference on Robotics and Automation (ICRA), pp. 5103-5109, 2019.

13. A. Gohritz: Schädigung peripherer Nerven der oberen Extremität. In: Praxis der Plastischen Chirurgie, pp. 353-359), Springer-Verlag, Berlin, 2011.

14. J. Felfe: Arbeits-und Organisationspsychologie 2: Führung und Personalentwicklung. Kohlhammer Verlag, Stuttgart, 2012.

15. J. C. Rüegg: Gehirn, Psyche und Körper. Schattauer Verlag (später Thieme-Verlag), Stuttgart, 2010.

16. W. Bieger: Neurostress - eine Analyse Teil 2. in: Zeitschrift für Orthomolekulare Medizin, pp. 31-33, Haug-Verlag, Stuttgart, 2014.

17. D. Michalski, A. Hinz: Schmerzchronifizierung bei ambulanten Rückenschmerzpatienten. Der Schmerz, vol. 20(3), 198-209, 2006

18. M. Daseking, D. Putz, D: TBS-TK Rezension. Psychologische Rundschau. Hogrefe-Verlag, Göttingen, 2015.

19. R. Weidner, B. Otten, F. Schroeter, J. P. Wulfsberg, P. Dehmel, T. Jacobsen: Effects of using exoskeleton - Physical and cognitive effects using the example of activities at head level and above. In: Werkstattstechnik (WT), vol. 108 (9), pp. 597-601, 2018.

20. R. Brickenkamp, L. Schmidt-Atzert, D. Liepmann: Test d2-Revision: Aufmerksamkeits-und Konzentrationstest. Hogrefe, Göttingen, 2010.

21. J. Cohen: Statistical Power Analysis for the Behavioral Sciences. Routledge Academic, New York, 1988.

22. C. G. Drury: The speed - accuracy trade-off in industry. Ergonomics, vol. 37(4), 747-763, 1994.

Open Access This chapter is licensed under the terms of the Creative Commons Attribution 4.0 International License (http://creativecommons.org/licenses/by/4.0/), which permits use, sharing, adaptation, distribution and reproduction in any medium or format, as long as you give appropriate credit to the original author(s) and the source, provide a link to the Creative Commons license and indicate if changes were made.

The images or other third party material in this chapter are included in the chapter's Creative Commons license, unless indicated otherwise in a credit line to the material. If material is not included in the chapter's Creative Commons license and your intended use is not permitted by statutory regulation or exceeds the permitted use, you will need to obtain permission directly from the copyright holder. 